Behavior and Social Issues, 27, 47-70 (2018). C Gleb Tsipursky, Fabio Votta, \& Kathryn Roose. Readers of this article may copy it without the copyright owner's permission, if the author and publisher are acknowledged in the copy and the copy is used for educational, not-for-profit purposes. doi: 10.5210/bsi.v.27i0.9127

\title{
Fighting Fake News and Post-Truth Politics With Behavioral Science: The Pro-Truth Pledge
}

\author{
Gleb Tsipursky ${ }^{1}$ \\ The Ohio State University \\ Fabio Votta \\ University of Stuttgart \\ Kathryn M. Roose \\ University of Nevada, Reno
}

\begin{abstract}
We have witnessed an alarming deterioration of truth in democracies around the globe, especially in the political arena. This paper describes a proposed intervention, the Pro-Truth Pledge (PTP), which combines behavioral science research with crowd-sourcing to help address this problem. The PTP asks signers - private citizens and public figures - to commit to 12 behaviors that have been shown to be correlated with an orientation toward truthfulness. Pledge mechanisms have been shown in other contexts to lead private citizens to engage in more pro-social behavior. For public figures, the PTP offers specific incentives to behave in concordance with the Pledge, with rewards in the form of positive reputation for honesty and truth-telling, and accountability through crowd-sourced evaluation and potential aversive consequences contingent upon deception. A study conducted on the PTP has demonstrated its effectiveness in reducing the sharing of misinformation on social media. These preliminary findings suggest that the PTP may be an effective intervention for addressing at least some of the problems caused by fake news and posttruth politics.
\end{abstract}

KEYWORDS: deception, post-truth politics, fake news, alternative facts

\section{The Era of Post-Truth Politics}

Few would dispute that many have lied to achieve their political agendas in the past. However, the recent and current political climate will arguably be recalled by future generations as the time of "fake news," "alternative facts," and an explosion of viral untruths on the ever-expanding worldwide social network. Recent political events, such as the tactics used by Donald Trump's campaign during the 2016 U.S. presidential election, and lies spread in the "Vote Leave" campaign in the U.K. Brexit referendum, have resulted in the venerable Oxford Dictionary choosing as the 2016 word of the year post-truth, "circumstances in which objective facts are less influential in shaping public opinion than appeals to emotion and personal belief" (Oxford Dictionary, 2016, n.p.).

In an example of post-truth politics, The Washington Post's well-respected Fact Checker compared the two major candidates in the U.S. presidential election in early November 2016 and found that Trump received the worst rating 63 percent of the time, while Hillary Clinton received

\footnotetext{
${ }^{1}$ Authors may be contacted at gleb@intentionalinsights.org.
} 
the worst rating 14.2 percent of the time. Previously, U.S presidential candidates received the worst rating between 10 and 20 percent of the time (Cillizza, 2016).

Post-truth politics also describes a new model of behavior when caught lying. Unlike politicians who confess or change position when caught, post-truth politicians do not back away from their falsehoods. Instead, they attack those who point out their deceptions, undermining public trust in credible experts and reliable news sources. This may help explain why trust of the media among Republicans has fallen by more than half, from 32 to 14 percent, from September 2015 to September 2016 (Swift, 2016), as Donald Trump (a Republican) is famous for calling the media "fake news" and suggesting on his Twitter feed that the media distributes "purposely false and defamatory stories" (Huppke, 2017).

\section{Fake News and Social Media}

The pervasiveness of social media has had an exponential impact on spreading non-truths. According to the Pew Research Center, seven out of ten Americans use social media. Twitter, Trump's social media platform of choice, reported 330 million users by the end of 2017 (Statista, 2017). Facebook is the most popular, with 68 percent of U.S. adults using it, and 74 percent of users logging in daily (Pew Research Center, 2018). According to Baum (1994), a large portion of conditioned reinforcers and punishers are social in nature. Thus, social media provides a virtual social community within which behavior may be reinforced or punished by those in one's social network. Arguably, this social network is often more extensive than one's "real life" social network in terms of numbers, in terms of access to each other's lives. Facebook users have more access to the verbal behavior of their Facebook friends than their real life friends, who may go months or years without communicating in person.

The impact of sharing misinformation is vast. Sixty-two percent of U.S. adults contact news on social media (Gottfried \& Shearer, 2016). A poll by Ipsos, conducted in late November and early December 2016, showed that American adults are prone to be deceived by fake news headlines. Surveying 3,015 adults, participants were shown six election-related headlines, three fake and three true, and asked if they had previously read the headlines. In the case that they had read the headline, the respondents were asked to rate the headline as "very accurate," "somewhat accurate," "not very accurate," or "not at all accurate." Of those who had read the fake electionrelated headlines, approximately 75 percent rated the headlines "very accurate" or "somewhat accurate." Participants who self-identified as Republicans were slightly more likely to be fooled by fake news, rating fake news headlines as accurate 84 percent of the time, compared to 71 percent of participants who self-identified as Democrats (Silverman \& Singer-Vine, 2016).

A study that compared true and fake election-related news stories on Facebook by the number of engagements - reactions, comments, and shares - showed that in the three months before the U.S. presidential election, the top 20 fake election-related news stories received more engagements than the top 20 real news stories, 8,711,000 compared to 7,367,000 (Silverman, 2016). Another study, which looked at a wider number of fake news stories, showed that in the same period of three months before the 2016 U.S. Presidential election, 156 misleading news stories got just under 38 million shares on Facebook (Allcott \& Gentzkow, 2017). Note that the researchers in this study only examined shares on Facebook rather than engagements. The latter number would have been much higher. The same study showed that fake stories favorable to Donald Trump were shared 30 million times, while fake stories favorable to Hillary Clinton were shared a total of 7.6 million times, suggesting that fake news leading up to the election favored the conservative perspective. 
Notably, the Washington Post recently reported on an unpublished study out of Ohio State University that found that fake news likely had a significant impact on the 2016 U.S. presidential election. The study found that around 4 percent of voters who supported Barack Obama for president in 2012 were influenced to not vote for Clinton on the basis of fake news stories. This includes 20 percent of Obama supporters who believed that Clinton approved weapons sales to Islamic jihadists, which is a news story that has not been verified by any fact-checkers. Of the 25 percent of Obama supporters who believed at least one fake story about Clinton, 45 percent did not vote for her. Of the 75 percent who did not believe any of the news stories, 89 percent voted for Clinton. A regression analysis indicated that of a variety of factors that may influence an Obama voter to not vote for Clinton, belief in fake news accounted for 11 percent of the variance, potentially affecting the outcome of the election (Blake, 2018).

Fake news comes from a variety of sources, but according to U.S. intelligence agencies, a major portion has originated from Russia's efforts to use digital propaganda to influence the U.S. election. Recent U.S. congressional investigations shed light on Russia's successful efforts (Kwong, 2017). Additionally, political partisans for either side, but especially Republicans, create massive amounts of fake news (Green \& Issenberg, 2016), as do people and entities attempting to benefit financially from spreading fake news (Subramanian, 2017).

Of course, the United States is far from unique in the impact of fake news. The United Kingdom was another target of Russian's digital propaganda effort, with researchers finding many hundreds of accounts operated by the Russian Internet Research Agency for the purpose of spreading fake news to influence U.K. politics (Booth, Weaver, Hern, \& Walker, 2017). Russiaowned accounts spread misinformation in Spain to incite the Catalonian independence movement (Palmer, 2017), and used misinformation to try to influence the 2017 German elections (Shuster, 2017). The 2017 French elections also drew a great deal of fake news, with a substantial amount coming from Russian-backed accounts (Farand, 2017). Those outside the United States are similarly susceptible to believing fake news when exposed to it. For example, a research study on misinformation in the 2017 French election found that exposing voting-age French people to deceptive election-related statements resulted in the study subjects believing presidential candidate Marine Le Pen's falsehoods.

The specific impact of candidates on their supporters sharing false information may be explained in part by research on emotional contagion, which shows that followers tend to emulate their leaders (Hatfield, Cacioppo, \& Rapson 1993). For example, individuals that support Donald Trump are more likely to believe what he says, view his behavior favorably, and attend to reinforcement of his behavior by others in their in-group. The result is an increased likelihood of imitating the behavior of Donald Trump.

\section{Truth and the Tragedy of the Commons}

Although our society as a whole suffers when deception is rampant in the public sphere, individuals who practice deceptive behaviors often do so to support or enhance their own agendas. This situation is reminiscent of a "tragedy of the commons," as described in Hardin's seminal article in Science (Hardin, 1968). Hardin demonstrated that among groups of people who share a common resource without any outside controls, each individual may benefit in taking more of the common resource than is his or her fair share, leading to individual gain at great cost to the community as a whole. Solving tragedies of the commons requires "mutual coercion, mutually agreed upon by the majority of the people affected" (Hardin, 1968, p. 1247) so as to prevent these 
harmful outcomes where a few gain at the cost of everyone else. In other words, contingencies must be arranged such that taking more than your fair share results in aversive consequences that outweigh reinforcers.

A societal example of a tragedy of the commons is environmental pollution (Vogler, 2000). Society as a whole benefits from clean air and water, yet individual polluters may gain more - at least in the short and medium term - from polluting (Hanley \& Folmer, 1998). The sustainability movement presents many examples of successful efforts to address the tragedy of the commons (Ostrom, 2015). As predicted by Hardin, only substantial disincentives for polluting outweigh the benefits (Fang-yuan, 2007). Particularly illuminating is a theoretical piece describing the application of psychology research to the tragedy of the commons in the environment. In addition to coercion by an external party such as the government, the commons can be maintained by a combination of providing credible information on what helps and hurts the environment, appealing to people's identities, setting up new or changing existing institutions, and shifting the incentives for participants (Van Vugt, 2009).

Research on successful strategies used by the environmental sustainability movement fits well with work on libertarian paternalism and choice architecture. Libertarian paternalism is a term that comes from behavioral economics that refers to an approach by private and public institutions to influence human behavior for social good while also respecting individual choice (Sunstein \& Thaler, 2003a; Sunstein \& Thaler, 2003b; Thaler \& Sunstein, 2008). Choice architecture is the method used by libertarian paternalists to design the way choices are presented to consumers to increase the probability of choosing the option that with the greatest personal and social benefit, such as healthy food choices and registering for organ donation. Methods in choice architecture include setting up default options, anticipating errors, giving clear feedback, and creating appropriate incentives (Johnson et al. 2012; Jolls, Sunstein, \& Thaler 1998; Selinger \& Whyte, 2011; Thaler et al., 2014).

With respect to the spread of fake news, a parallel may be drawn. While society as a whole is hurt by viral deception, there are some that benefit by the spread of lies, whether by deliberately lying to push their agenda or to align with a social group, by conserving response effort by sharing without checking, or by dismissing fact-checking and spreading misinformation that supports one's own views. Recent research by prominent scholars discussed the need for a variety of safeguards to protect our global society from fake news (Lazer et. al. 2018). Another article suggested that any effort to address the situation "must involve technological solutions incorporating psychological principles, an interdisciplinary approach that we describe as 'technocognition'” (Lewandowsky, Ecker, \& Cook, 2017, p. 353).

\section{A Proposed Intervention to Address Pollution of Truth: The Pro-Truth Pledge}

In response to the growing crisis regarding the spread of misinformation, the first and second authors of this paper have developed a technocognitive intervention termed the Pro-Truth Pledge (PTP). The PTP is informed by strategies that have proven successful in the sustainability movement combined with choice architecture. The Pledge asks signers to commit to 12 behaviors that research in psychology shows correlates with an orientation toward truthfulness. Early results show that both private citizens and public figures are willing to take the PTP, and interviews, external observations, and quantitative studies indicate that the PTP may be effective at reducing the spread of fake news. 


\section{Truth and Lies}

To consider interventions to increase truthful behavior, one must first examine the conditions under which one behaves untruthfully. For Skinner, a lie is a response emitted under circumstances that would otherwise control an incompatible response (Skinner, 1957). Skinner (1974) continues:

The truth of a statement of fact is limited by the sources of the behavior of the speaker, the control exerted by the current setting, the effects of similar settings in the past, the effects upon the listener leading to precision or to exaggeration or falsification, and so on. (p. 150)

Most otherwise honest adults would likely admit to lying in a variety of contexts to contact positive consequences, avoid negative consequences, or both. One may lie about their schedule to avoid dinner plans with an annoying person to avoid an unpleasant situation. Upon receipt of a gift, the receiver may falsely express great appreciation to salvage a friendly moment from which they derive reinforcement. These examples may be better described as untruthful verbal behavior under the control of competing contingencies. One contingency supports truthful behavior, likely under the control of a history of socially-mediated positive consequences for truthful behavior and negative consequences for untruthful behavior. The other contingency supports kind behavior, also likely under the control of a history of socially-mediated positive consequences for kind behavior and negative consequences for unkind behavior. In the case of untruthful behavior addressed by the PTP, there may be a variety of contingencies competing against honest behavior. For example, fact checking requires response effort above and beyond simply agreeing with or sharing a news story, and confronting friends (or even strangers) who share fake news may set up an aversive social contingency. Thus, interventions addressing the sharing of fake news should increase positive consequences for honesty relative to the consequences for the alternative.

Skinner (1971) presents an analysis of behavior that is for the good of the individual, for the good of others, or for the good of the group or culture. In Skinner's recommendations for designing a culture, he suggests that cultures should arrange contingencies to support individual behavior that benefits others, and the group (Skinner, 1971). Otherwise, the tendency of individuals is to behave in such a way to benefit themselves at the expense of the group. This suggestion mirrors the tragedy of the commons, in which individuals must choose between behaviors that benefit themselves or the group. This may be seen in the sharing of fake news to benefit one's agenda at the expense of the opposing agenda, or the general population.

Another relevant factor may be an individual's values. Skinner (1953) discussed values in terms of assigning labels of "good" and "bad," and describing what one "ought" to do. Describing a stimulus as good or bad simply describes the reinforcing effects of that stimulus. Similarly, "ought" describes behaviors that are likely to be reinforced. From a Relational Frame Theory (RFT; Hayes, Barnes-Holmes, \& Roche, 2001) perspective, values are verbal behavior that transform the psychological function of objects and events. Essentially, when one values honesty, the function of stimuli (e.g. verbal behavior, people) relating to honesty have a reinforcing function, and stimuli relating to dishonesty have a punishing function. Values also function as rulegoverned behavior, specifying consequences for behavior in relation to the rule (value). "Valuing honesty" predicts honest behavior. 


\section{Post-Truth Pledge Development}

Rule-Governed Behavior. The PTP is derived in part from research on precommitment, which suggests that those who commit to a certain behavioral norm will be more likely to follow it (Ariely \& Wertenbroch, 2002). As such, the PTP functions as a verbal discriminative stimulus, specifically a rule, describing a contingency in which certain behaviors (truthful) will be followed by positive consequences, and certain behaviors (untruthful) will be followed by negative consequences. The rule arranges contact with a relational network that transforms the functions of stimuli related to the relational network (Torneke, 2010) such that contact with truthful, untruthful, and unknown stimuli evoke relevant behavior aligned with the rule.

There are three types of rule-governed behavior described in RFT (Hayes et al., 2001): pliance, tracking, and augmenting. Taking a pledge may be conceptualized as pliance, which is "rulegoverned behavior under the control of a history of socially mediated reinforcement for coordination between behavior and the antecedent verbal stimuli" (Hayes et al., 2001, p. 108). Reinforcement is delivered upon coordination between the rule (a "ply") and behavior, and punishment may be delivered for discoordination with the rule, either from another person, or privately, as discrepancy between the rule and behavior may result in an aversive condition.

Tracking is rule-governed behavior under the control of the correspondence between the rule (a "track") and the way the world is arranged (Hayes et al., 2001). Tracks control behavior by determining how to behave to maximize existing reinforcers and avoid existing punishers (Hayes, Gifford, \& Hayes 1998). Hayes and colleagues (1998) provide an example of using the Golden Rule as a track, such that one may examine what functions as personal reinforcers and punishers to predict what may function as reinforcers and punishers for others. Thus, with the Golden Rule functioning as a track, one may "do unto others" because that makes it more likely that others will "do until you" (p. 260). In terms of the PTP, tracking may describe the commitment of honest people to spreading the truth as lies are likely personally aversive, and the assumption may be made that lies are aversive to others as well.

Additionally, augmenting may be used to describe the PTP. Augmenting is "rule-governed behavior due to relational networks that alter the degree to which events function as consequences" (Hayes et al., 2001, p. 109). Augmenting accompanies either pliance or tracking, altering the reinforcing or punishing strength of the specified consequences. Motivative augmenting is behavior aligned with a rule that alters the effectiveness of an already-established reinforcer or punisher in certain contexts. Augmenting has been related to what is commonly called "motivation" outside of the field of behavior analysis (Torneke, 2010). For individuals for whom truthfulness is already covered by a contingency of reinforcement, the PTP may function as a motivative augmental, increasing positive consequences for truthful behavior, and increasing negative consequences for untruthful behavior.

Pledges such as the PTP are voluntary, and therefore function as self-rules, which are rules that are directed towards oneself to influence one's own actions (Torneke, 2010). However, by making the pledge public, the signer is arranging for social participation in the contingencies around the pledge. According to Skinner (1974), "The verbal community of the scientist maintains special sanctions in an effort to guarantee validity and objectivity" (p. 150).

Cognitive Biases. Beyond rule-governed behavior, there are a number of cognitive biases that contribute to people believing in and sharing misinformation. Cognitive biases have been conceptualized by behavior analysts as relating to motivating operations and verbal behavior (Wray, Freund, \& Dougher, 2009). Motivating operations (MOs) increase the value of 


\section{THE PRO-TRUTH PLEDGE}

reinforcement for a given response and increase the likelihood of that given response (Michael, 1982). Relatedly, MOs affect the stimulus control of environmental stimuli, resulting in increased attending to relevant stimuli and decreased attending to irrelevant stimuli. If one is hungry, an MO is in effect, resulting in a condition that supports attention to stimuli related to food rather than stimuli not related to food. (Wray et al., 2009).

One of the biases the PTP aims to address is the confirmation bias (Nickerson, 1998), which may also be explained by stimulus control. Individuals may alter their behavior to avoid the punishment of political others, allocate more of their behavior to those who are more likely to reinforce their behavior relating to politics, and more importantly, selectively attend to stimuli related to reinforcement for their political beliefs and selectively ignore stimuli related to punishment. In other words, they will be more likely to attend to and share news stories in support of their candidate and ignore or argue against news stories supporting other views. Research shows that one way to address the confirmation bias involves asking people to attend to and search for evidence that disproves their initial beliefs (Hirt \& Markman, 1995; Kray \& Galinsky, 2003; Lilienfeld, Ammirati \& Landfield, 2009).

Another contributor to sharing fake news is in-group bias, a description of the tendency of behavioral repertoires to align with the repertoires of others that people perceive to be part of their own group, and vice versa for those who they perceive as part of their out-group (Mullen, Brown, \& Smith, 1992; Verkuyten \& Nekuee, 1999). This is a real issue on social media, as studies have indicated that following the especially contentious presidential election of 2016, there has been a trend to "unfriend" those who identify with the opposing political party (e.g., Lindner, 2016), resulting in an environment that supports in-group bias, and does not support fact checking. Research shows that people are more likely to lie if it is likely to benefit their in-group (Mazar, Amir, \& Ariely, 2006). Thus, people are more likely to share articles favorable to their in-group without fact checking even if the article inspires some skepticism. Promotion of questionable content favorable to one's in-group indicates shared values, is likely to result in positive consequences for behavior that supports the mutual cause, and increases group social reinforcement.

An additional factor is choice-supportive bias (Correia \& Festinger, 2014), in which interpreting our own choice behavior negatively is likely to result in an aversive condition, so we may attend only to stimulus relations that favor that choice. For example, if one has a choice between buying a Ford or a Honda and buys the Ford, attention to stimuli that support the value of the Ford will be enhanced to reinforce the decision, while attention to stimuli that support the value of the Honda will be suppressed to avoid the aversive condition of "making the wrong decision." This relates to fake news as people may be more likely to attend to and share news that supports their previous choices (e.g., the selection of a political party or candidate).

A related bias is cognitive dissonance (Festinger, 1975), which refers to the idea that "if a person knows various things that are not psychologically consistent with one another, he will, in a variety of ways, try to make them more consistent" (Festinger, 1962). According to Festinger (1962), dissonance impels people to change their opinions or behavior to alleviate the discomfort brought about by dissonance. RFT suggests that verbal coherence functions as a reinforcer for verbal behavior itself, and verbal inconsistency is a punisher for "most members of the verbal community” (Roche, Barnes-Holmes, Barnes-Holmes, Stewart, \& O'Hora, 2002, p. 88). Thus, sharing news inconsistent with one's position may result in the aversive condition of dissonance, making one less likely to share that type of story, and more likely to share stories in line with their position, regardless of the veracity. 


\section{TSIPURSKY, VOTTA, \& ROOSE}

A related phenomenon is a preference for consistency, as research suggests people are likely to make decisions that are consistent with their past decisions (Guadagno \& Cialdini, 2010), provided that the past behavior has been reinforced, or at least not punished. Making responses consistent with previously reinforced responses as opposed to untested responses may increase the likelihood of reinforcement.

\section{The Pro-Truth Pledge}

The Pro-Truth Pledge was developed with all of the preceding research in mind, with components to address each bias and behavior change strategy. The full pledge reads as follows:

I Pledge My Earnest Efforts To:

Share the truth

- Verify: fact-check information to confirm it is true before accepting and sharing it

- Balance: share the whole truth, even if some aspects do not support my opinion

- Cite: share my sources so that others can verify my information

- Clarify: distinguish between my opinion and the facts

Honor the truth

- Acknowledge: acknowledge when others share true information, even when we disagree otherwise

- Reevaluate: reevaluate if my information is challenged, retract it if I cannot verify it

- Defend: defend others when they come under attack for sharing true information, even when we disagree otherwise

- Align: align my opinions and my actions with true information

Encourage the truth

- Fix: ask people to retract information that reliable sources have disproved even if they are my allies

- Educate: compassionately inform those around me to stop using unreliable sources even if these sources support my opinion

- Defer: recognize the opinions of experts as more likely to be accurate when the facts are disputed

- Celebrate: celebrate those who retract incorrect statements and update their beliefs toward the truth

Each component of the PTP is designed to counteract contributing factors to sharing fake news. To ensure full clarity on what constitutes violations, the PTP defines misinformation as anything in opposition to objective truth, such as directly lying, lying by omission, or misrepresenting the truth. While sometimes misinformation is blatant, at other times it is more difficult to identify, and for these tough calls, the PTP asks signers to utilize credible fact-checking 
organizations - the same ones that Facebook uses for its fact-checking program - and/or scientific consensus, as recognized by meta-analyses and statements from influential scientific organizations. Researchers have found that fact-checking improves the likelihood that people believe actual facts (Barrera, Guriev, Henry, \& Zhuravskaya, 2017). Fact-checking provides the opportunity for behavior change if one does not find credible evidence supporting that information. ${ }^{2}$ This aspect of the PTP addresses the extensive sharing of fake news, both by private citizens and by public figures (Allcott \& Gentzkow, 2017).

The PTP also addresses the repeated sharing of incorrect information, which produces the illusory truth effect, the belief that a false statement is true due to multiple exposures to the untruth (Fazio, Brashier, Payne, \& Marsh, 2015). Multiple contacts with a false statement that is associated with reinforcement or lack of punishment may strengthen the reinforcing effects of the statement. For example, if a child hears adults repeat statements that seem untrue, but are never punished or challenged, the child may believe the untruths after enough exposure.

Signers are asked to reduce impulsive behavior by pausing and verifying before sharing information, which has been correlated with making fewer errors and facilitating analytical thinking to counteract belief bias (Pennycook, Cheyne, Koehler, \& Fugelsang, 2013). Impulsive verbal behavior may be under incomplete stimulus control, increasing the likelihood of deviations from the truth. In the spirit of anticipating errors, an important aspect of choice architecture, the PTP encourages signers to provide positive consequences for others and themselves for retracting incorrect statements and updating their beliefs toward the truth.

To address in-group bias, the PTP asks signers to defend others who come under attack for sharing accurate information even if they have different values, and to request that those who share inaccurate information retract it, even if they are their friends and allies. The Dunning-Kruger effect describes another cognitive bias in which those who have less expertise and skills in a given area have an inflated perception of their abilities; in other words they are ignorant of their own ignorance (Dunning, 2011; Ehrlinger, Johnson, Banner, Dunning, \& Kruger, 2008; Kruger \& Dunning, 1999; Sheldon, Dunning, \& Ames, 2014). To address this problem, the PTP calls on signers to "recognize the opinions of those who have substantially more expertise on a topic than myself as more likely to be accurate in their assessments."

In addition to the cognitive biases that facilitate deception, other studies have emerged on contingencies that support honest and dishonest behavior. If people perceive others around them as behaving dishonestly, they are more likely to behave dishonestly themselves; conversely, if one behaves dishonestly, they perceive others as more likely to behave dishonestly (Gino, Norton \& Ariely, 2010). These two patterns together create an iterative spiral of deception. For instance, consider social media sharing of viral deception. One who spreads deceptive content will perceive others as more likely to spread viral deception; likewise, if that person sees someone else sharing misinformation, they will be more likely to share viral deception themselves, as that person's actions provide implicit permission to do so.

Research on interventions to support honest behavior have found efficacy of reminders about ethical behavior, making standards for truthful behavior clear, and signing honor codes and other types of pledges (Mazar, Amir, \& Ariely, 2008a; Mazar, Amir, \& Ariely, 2008b). Examples of the latter include research that indicates that in schools that have honor codes students tend to engage in less academic dishonesty (McCabe \& Trevino, 1993; McCabe, Trevino, \& Butterfield, 1999),

\footnotetext{
2 The full text of the statement on what the PTP considers misinformation may be found at https://www.protruthpledge.org/misinformation/
} 
and those who commit to recycling by signing a pledge were more likely to follow on their commitments in comparison to those who just agreed to recycle (Katzev \& Pardini, 1987).

Our likelihood of lying is strongly impacted by our social network, making it especially important to address social norms around deception (Mann, Garcia-Rada, Houser, \& Ariely, 2014). Ariely and Jones (2012) summarize and synthesize the research on contingencies that support lying and telling the truth in their book The Honest Truth About Dishonesty: How We Lie to Everyone--Especially Ourselves. Deceptive behavior is highly related to self-identity and group belonging. Self-identity is attention to one's own behavioral repertoires, and when individuals behave in line with publicly or privately communicated values (e.g., honesty), that concordance may result in derived reinforcement. Group belonging may impact truth-related behaviors if the group norms favor honesty. Thus, inducing a greater orientation toward the truth requires integrating truthoriented behaviors into one's identity and group affiliation. The more of these factors a solution can address, the higher the likelihood of increasing truthful behavior.

\section{The Pro-Truth Pledge: Private Citizens}

We promoted the PTP to private citizens in three ways. First, PTP supporters with some name recognition go on various radio shows and other public media to spread word about it, which results in a number of people signing. Second, we encourage pledge-takers to share about taking the PTP with their social network, online and in-person, which brings in additional signers. Third, PTP volunteers do canvassing for and public speaking about the PTP, which also brings in signers.

Why do private citizens sign? Many find the prevalence of deception in our society highly aversive, especially in the political system. Signing the PTP gives private citizens an opportunity to publicly communicate their discontent, encourage the movement of our society toward greater honesty, and increase the credibility of signers among their peers, as it indicates the strength of a behavioral repertoire aligned with honesty. Signers are given access to resources such as a search engine composed of credible sources verified as reliable by the PTP organizers (Pro-Truth Pledge Search Engine). Signers also have the opportunity to join a variety of closed communities both online and in their local area where they can rely on the credibility of the information being shared by other signers of the PTP, and where they can support and encourage each other in practicing behaviors advocated by the PTP.

The PTP encourages signers to share about it on their social media and personal networks, and to put a badge on their online presence indicating they signed it (Pro-Truth Pledge Badge). As peer support has proven helpful in maintaining behavior change in contexts such as health behaviors, and we anticipate that such support will help maintain truth-oriented behavior (Westman, Eden, \& Shirom, 1985; Zimmerman \& Connor, 1989). The PTP appeals to people's identities by asking those who self-identify as truthful and honest to take the pledge and join the community of pledge-takers. This appeal to identity is informed by psychology research on the environmental sustainability movement that showed that people who report self-identification with a community tend to engage in behaviors condoned by that community (Van Vugt, 2001).

Pledge-takers have an opportunity to participate in PTP community-oriented activities inperson and online, to sign up for email updates and action alerts, to be listed in a public database of people who signed the PTP, and to share publicly about taking the PTP. They can also sign up to be a PTP advocate, which consists of any of the following: 1) Promoting the PTP to other private citizens; 2) Advocating for public figures to take the PTP; 3) Monitoring and evaluating whether the public figures who have signed the PTP stick to their commitment. In the initial PTP sign-ups, 
which amounted to 7500 pledge-takers, about 80 percent signed up for email updates and action alerts, about 60 percent chose to be listed in a public database, and about 20 percent indicated an interest in being a PTP advocate.

We hypothesize that the activities listed above will make it more likely that signers will abide by the tenets of the PTP due to increased contact with PTP-related content, and therefore increased stimulus control. Conversely, we suspect that those who sign the PTP without signing up for other forms of active engagement will have a small or perhaps negligible long-term impact on their behaviors, due to the minimal stimulus control. Still, given that people who have committed to recycling by signing a pledge did practice recycling at a higher rate than those who did not sign the pledge, we may indeed witness some impact by simply signing the PTP without additional participation.

Research on recycling shows that being given information about conservation resulted in increased pro-environmental behavior (Oskamp et al., 1991). Receiving email updates about the PTP would serve a similar function. Studies on recycling also show that having access to recycling opportunities increased the likelihood of recycling (Vining \& Ebreo, 1992), and the action alerts fill that function for the PTP, by alerting signers about opportunities to engage in PTP-related activities.

Knowing that one is being monitored for recycling and that negative messages for not recycling may be provided has been shown to increase recycling behavior (Lord, 1994). The parallel for the PTP is choosing to list oneself in a public PTP database and sharing with social networks that one took the PTP, thus setting up a contingency for public monitoring. Studies of buying environmentally-friendly products showed that such purchases stemmed in part from the opportunity to signal environmental friendliness to others as a form of status-seeking. Sharing about the PTP would similarly signal truth-friendliness (Griskevicius, Tybur, \& Van den Bergh, 2010).

Active volunteering and community engagement in recycling programs, such as block-leader programs, proved even more effective in increasing recycling behavior (Burn, 1991; Hopper \& Nielsen, 1991). By analogy, we anticipate that those who engage actively in PTP volunteering and community-oriented activities, online and in-person, will be even more likely to exhibit truthoriented behaviors. After all, community participation shapes self-identity and social norms, which research has found are important in supporting truth-telling behavior.

\section{The Pro-Truth Pledge: Public Figures}

Public figures find out about the PTP mainly through personal outreach. Many officials take the PTP because their constituents ask them to do so, for example. Likewise, public intellectuals learn about and take the PTP due to networking through private connections. What about the motivations of public figures? We anticipate that some public figures will be motivated by the same contingencies that would lead private citizens to take the PTP. However, for public figures, we wanted to provide customized positive reinforcement for abiding by the PTP and aversive contingencies for breaking the PTP, both in the form of reputation. Reputational rewards and penalties have been shown to be vital in addressing tragedies of the commons (Milinski, Semmann, \& Krambeck, 2002), and reminders about the reputation costs of making false statements proved effective at reducing misinformation shared by political candidates (Nyhan \& Reifler, 2015).

Taking the PTP is a way of indicating commitment to the truth to an audience interested in such information, thus providing a substantial reputational reward in the form of increased support 
by those who value the truth. When signing the PTP, public figures have an opportunity to provide a brief statement about why they took the PTP, and links to their online presence. This information is stored in a database that anyone can access, including constituents interested in evaluating political candidates for office or deciding whether to trust the commentary of a media figure, policy expert, or academic commenting on public affairs. Moreover, the statement is included in a regular newsletter sent to all PTP signers who subscribed to email updates. Doing so may improve that public figure's reputation and may result in new supporters who are also committed to truth and honesty. The public figures have the opportunity to provide additional content for the PTP newsletter about how the PTP changed their behavior, further boosting their reputation and providing evidence of the effectiveness of the PTP, creating a virtuous cycle characteristic of successful innovations (Casadesus-Masanell \& Ricart, 2011).

Such provision of information has been crucial in successful interventions within the environmental movement to address tragedies of the commons. As an example, research shows that labels on household appliances that list comparisons of energy use and emissions are most effective at changing behavior when consumers are already concerned with the environment but lack technical knowledge about appliances (Dietz, Ostrom, \& Stern, 2003). Similarly, many consumers of political information lack knowledge about which officials and media figures and analysts are credible, and the PTP provides that information.

Many may worry about the problem of false signaling or cheating - a public figure may take the PTP to signal a commitment to the truth, without actually abiding by it (Connelly, Certo, Ireland, \& Reutzel, 2011). Private citizens have little incentive to engage in responses that include sharing their personal data by filling out the PTP, making it likely that only those committed to advancing the cause of truth in our society would take this action. Essentially, the contingencies of reinforcement for taking the PTP must outweigh the effort in taking and abiding by it. However, the reputational value for public figures of taking the PTP is likely to grow, especially as the PTP gains popularity and credibility and has a larger email list. If false signaling and cheating are not prevented, the PTP will not be able to provide credible information and thus fail to shift incentives to favor sharing accurate information instead of deception. Additionally, as public figures who sign the PTP may be more susceptible to fact-checking, signers behaving contrary to the guidelines will be more vulnerable than public figures who do not sign the PTP.

To address cheating, the PTP involves a monitoring mechanism that arranges aversive contingencies in the form of reputational penalties which are commensurate with the infraction. Some PTP advocates are assigned the duty of monitoring public figures. If an advocate suspects that a public figure violated the PTP, the advocate will contact the individual privately, with an approach of "innocent until reasonably shown guilty" perspective - perhaps the person misspoke, or the advocate misunderstood. If the public figure withdraws the statement, or the advocate finds no actual violation of the PTP, the matter ends there.

If the advocate still believes the PTP was violated, the advocate may escalate the matter to PTP mediating committee. While anyone who signs the PTP may become an advocate, mediating committees are composed of a group of vetted volunteers who will evaluate the evidence provided by the advocate, contact the public figure to give them a chance to offer a defense, and make a ruling. If there is a ruling of a violation, the ruling is evaluated by a member of the PTP Central Coordinating Committee to ensure fairness and accuracy and to provide an external perspective. In the case that the PTP Central Coordinating Committee also determines that a violation has occurred, the Committee will contact the public figure offering a final chance to retract the 
statement. If the public figure still refuses to correct the inaccuracy, the PTP mediating committee will rule the public figure to be in contempt of the PTP.

Once someone is found to be in contempt of the PTP, the mediating committee will put reputational pressure on the individual to repeal the offending information. The committee would issue a press advisory to relevant media that the public figure is in contempt of the PTP. It will also issue an action alert either at the local, regional, or national level (depending on the stature of the public figure) for PTP signers to email, tweet, call, write, and protest in front of the office of the public figure encouraging the person to revise the relevant statement, and writing letters-tothe-editor about the situation. Finally, the public figure will be listed on the PTP website as being in contempt of the PTP. We anticipate that these consequences will provide considerable pressure for a public figure to avoid being in contempt of the PTP.

This complex process minimizes the possibility of the PTP being politicized or corrupted at a local level, a concern raised during in the formulation of the PTP. Indeed, research on the environmental movement showed that for an institution such as the PTP to succeed in gaining trust and credibility, it needs to demonstrate transparent, clear, and fair rules and procedures where all participants have the opportunity to make their case. For instance, research on the California water shortage in 1991 showed that people cooperated with drastic water-saving measures only if they believed the authorities listened to the concerns of all citizens, and they provided clear, accurate, and unbiased information (Tyler \& Degoey, 1995).

So why should elected or appointed officials take the PTP if it restrains their activities and may lead to retractions and admissions of untruthfulness? Officials need to be perceived as trustworthy by citizens. The PTP provides that credibility, due to the presence of the monitoring mechanism. If officials have signed the PTP and are not in contempt, citizens may assume the officials have not made any deceptive statements, or if they have, they have retracted them upon notification from a PTP signer. This provides the official with a reputation as being honest and credible, which may result in additional support. There is an additional benefit for candidates whose opponents have not taken the PTP, since the official can raise questions about why the opponent does not wish to take the PTP. The PTP thus offers a first mover advantage for those public officials who take it early onward (Kerin, Varadarajan, \& Peterson, 1992).

Over 500 politicians have already taken the PTP. The following are examples of statements from two politician pledge-takers:

As a progressive who has always valued learning to make our society better, as a Democrat who believes in ethics and transparency in government and politics, as a lifelong student and teacher who has always been devoted to the sciences, humanities, and all forms of study, I will tell the truth, promote the truth, and live the truth. I will stand against not only my opponents, but my own co-partisans if need be, to honor the truth in the face of falsehood. I am running for the US House of Representatives in the Texas 19th Congressional District in 2018. http://www.danepsteinforwesttexas.com/ (Democrat Dan Epstein)

I feel it is time to bring the country back together and this can not be done the way congress is acting now in an us vs them mentality. Most congressmen have only one goal and that is to get reelected. Congressmen will say whatever they need to in order to accomplish that goal truth or not. I pledge to work toward the truth and to be willing to speak the truth even if it is not in my best interest politically. I am a Republican running for Congress in Ohio's 
District 12: https://www.facebook.com/Baumeister-for-Congress-1682557778660008/ (Republican Jay Baumeister)

The statements are specifically crafted to appeal to people who care about honesty. Thus, the effects of the reputational incentives of the PTP are visible for these two candidates.

What about policy experts, commentators, analysts, media figures, and scholars? They all benefit from being perceived as trustworthy by the audiences to which they communicate. The PTP provides the benefit of the monitoring mechanism, such that the longer they are signed up without being in contempt, the more credibility they may earn. Those who sign may be able to reach a broader audience as a result of their information being included in the PTP updates. Moreover, if their competitors do not sign the PTP, those who signed up may attract a larger audience, as some individuals may engage in behaviors supported by preference for more trustworthy sources of news/analysis/thought leadership. Thus, the first mover advantage applies to these groups as well. In one example, conservative radio and podcast host, John Wells released the following statement upon taking the PTP:

The lifeblood of my program to which my name is attached and therefore all who I call and who call me, friend, those who trust me to be honest with them, and most importantly in the Earthly realm, my family rely on truthfulness in what I do. And of supreme importance, God is watching. And listening. www.caravantomidnight.com

Liberal radio hosts are taking the PTP as well, for example Ethan Bearman, rated the \#57 talk show host in the country by Talkers magazine and frequent guest on CNN and Fox. His statement is as follows:

Facts matter and the truth matters. With the state of communications allowing any bit of information, true or not, to instantly propagate across the globe, getting to the truth is as hard as its been in my memory. There are people who prey on others with falsehoods for monetary gain, political influence, and even pure malice. It is up to us to make sure the truth shines through the clouds of falsehoods. www.ethanbearman.com facebook.com/ethanbearmanshow twitter.com/ethanbearman Thank you! (Ethan Bearman)

Wells and Bearman crafted their statements to target audiences that care about the truth, and to get the appropriate reputation boost. Since both of these talk show hosts announced their commitment to the PTP on their programs, their listeners are now holding them accountable, along with PTP advocates who are assigned to this task.

\section{Alternatives and Challenges}

The current methods for advancing truth in our political system include the work of factchecking organizations. These much-needed efforts unfortunately do not address the underlying problem of distrust in fact-checking organizations. For instance, according to a September 2016 Rasmussen Reports survey, only 29 percent of likely voters in the United States trust fact-checking of candidates' statements. The political disparity is enormous, and in-line with previous reporting on the partisan divide - 88 percent of Trump supporters do not trust fact-checkers, compared to 41 percent of Clinton supporters (Rasmussen Reports, 2016). This distrust for fact-checkers will not be solved by providing more fact-checking or faster, real-time fact-checking. Indeed, research 
shows that real-time fact-checking may actually make people more resistant to correct information (Garrett \& Weeks, 2013). Such distrust may be addressed by increasing the value of the truth and by providing credible information about who is truthful. The PTP aims to solve these problems by appealing to people's identities and values, arranging contingencies in support of truth-oriented behavior, and providing information identifying honest public figures. A secondary effect of the PTP may be to help legitimate trustworthy fact-checking organizations. Research suggests that training in media literacy is likely to reduce perceptions of bias by the media in reporting on controversial news stories, and the behaviors of the PTP are conducive to higher media literacy (Vraga, Tully, \& Rojas, 2009).

While the behavioral principles supporting pledges appear to be scientifically valid, the outcomes of pledges have been mixed. For example, virginity pledges have been shown consistently to delay the onset of sexual behavior (Martino, Elliott, Collins, Kanouse, \& Berry, 2008). However, other research has shown that rates of sexually transmitted diseases are comparable among those who took a virginity pledge and those who did not, potentially due to lower rates of condom use and testing by those took the pledge (Brückner \& Bearman, 2005). Thus, the PTP may have mixed results in reducing the behavior of sharing misinformation. Public figures may avoid signing the PTP if they observe others suffering reputational damage following behavior in contempt of the PTP. On the other hand, politicians, media venues, and others who benefit from deceiving voters may become more likely to take the PTP as they see it gain ground.

Regarding potential bias in selecting fact-checking organizations, the PTP specifically aligned with the same fact-checking organizations that Facebook uses, since Facebook has a huge financial interest in using only the most high-quality fact-checking venues. Moreover, the PTP - unlike factchecking organizations - only evaluates those who have chosen to sign the PTP; it is an opt-in mechanism, like the Better Business Bureau, as opposed to fact-checkers who fact-check statements that the fact-checking organization finds relevant.

Another finding that might be potentially problematic for the effectiveness of the PTP is that citizens often use political figures they support as a guide to what they consider true or false, regardless of the facts (Swire, Berinsky, Lewandowsky, \& Ecker, 2017). The PTP may serve citizens by publicizing politicians who have a track record of telling the objective truth. Indeed, a number of PTP signers have expressed that they would consider whether a candidate has taken the PTP a strong factor in choosing candidates to support with their votes, money, and time.

\section{Pro-Truth Pledge Impact: Anecdotal Evidence}

The PTP was launched in December 2016, and by May 2018 had over 7500 pledge-takers. Over 1200 are public figures, including such prominent names as philosopher Peter Singer, cognitive psychologist Steven Pinker, Michael Shermer, the publisher of Skeptic Magazine and columnist for Scientific American, and social psychologist Jonathan Haidt. Of the public figures who have signed the PTP, over 500 are politicians, including members of state legislatures Eric Nelson (PA), James White (TX), and Ogden Driskell (WY), and members of US Congress Beto O'Rourke (TX), Matt Cartwright (PA), and Marcia Fudge (OH) . There are also over 70 organizations that have signed the PTP, including Media Bias/Fact Check, The National Compass, Columbus Free Press, Fugitive Watch, and Earth Organization for Sustainability. Online and inperson groups dedicated to the PTP have emerged in over 20 states and are starting up in other states as well as abroad. 
When asked why they took the PTP, people generally reported a desire to cast a vote against fake news and demonstrate a personal commitment to honesty. Some also discussed the desire to project a reputation as truth-tellers for the sake of gaining greater credibility among those with whom they engage.

Follow-up conversations with and writings by pledge-takers have indicated the impact of the PTP on their behavior. A private citizen, U.S. Army veteran John Kirbow, stated that after taking the PTP, he felt "an open commitment to a certain attitude" to "think hard when I want to play an article or statistic which I'm not completely sold on." He found the PTP "really does seem to change one's habits," encouraging him to correct his own mistakes with an "attitude of humility and skepticism, and of honesty and moral sincerity," and to encourage "friends and peers to do so as well." Christian pastor and community leader Lorenzo Neal described how he "took the ProTruth Pledge because I expect our political leaders at every level of government to speak truth and not deliberately spread misinformation to the people they have been elected to serve. Having taken the pledge myself, I put forth the effort to continually gather information validating stories and headlines before sharing them on my social media outlets."

Others who participated in follow-up conversations shared similar responses. It is important to note that follow-up conversations are limited by two factors: self-selection and self-reporting. After all, those likely to respond are those who find the PTP beneficial and impactful. To address this concern, we observed the behaviors of pledge-takers, and have observed instances where the PTP prompted individuals to retract statements determined to be untruthful.

For instance, a candidate for Congress, Michael Smith, took the PTP. He later posted on his Facebook wall a screenshot of a tweet by Donald Trump criticizing minority and disabled children. After someone identified the tweet as untruthful and confronted him about it, Smith accessed Trump's Twitter feed. He was unable to find the tweet he posted, and although Trump may have deleted that tweet, the candidate edited his own Facebook post to say that "Due to a Truth Pledge I have taken I have to say I have not been able to verify this post" (Imgur, 2017). Smith further posted that he would be more careful with future postings to ensure truthfulness. In another case, Mark Kauffman, a photographer from New York, shared an article from OccupyDemocrats.com, a site shown by credible fact-checkers used by the PTP to be systematically unreliable. Other pledge-takers, who have thereby committed to ask others to stop using unreliable sources regardless of the credibility of the article, asked him to withdraw it, and he did so.

\section{Pro-Truth Pledge Impact: Empirical Evaluation}

While anecdotal evidence have been illuminating regarding the effects of the PTP, empirical studies would provide better evidence of its efficacy. Thus, we designed a study to evaluate the effects of taking the PTP on social media posting. We targeted Facebook, as the most popular social media platform, with 44 percent of U.S. adults reportedly accessing news via Facebook in 2016 (Pew Research Center, 2016).

\section{Method}

To avoid reactivity of study participants being impacted by observation, the study did not evaluate current behavior, but past behavior. We recruited participants via Facebook posts and emails to individuals who took the PTP and signed up to receive updates, including solicitations for participation in a study about the PTP. Participants were not given any incentives to participate. With these limitations, we were able to secure 21 participants (see Table 1). 
THE PRO-TRUTH PLEDGE

Table 1

Descriptive statistics

\begin{tabular}{cccc}
\hline Time & $\mathrm{N}$ & Mean & SD \\
\hline Before Truth-Pledge & 21 & 2.49 & 0.60 \\
After Truth-Pledge & 21 & 3.65 & 0.41 \\
\hline
\end{tabular}

Participants granted access to their Facebook profile to researchers, enabling researchers to take advantage of the Facebook Timeline feature to evaluate posts made by study participants after they took the PTP. Thus, the quality of sharing by study participants was not impacted by them knowing they were being observed, since they enrolled in the study after they already made the Facebook posts that the researchers evaluated.

Researchers looked at the first ten Facebook posts with news-relevant content made four weeks after taking the PTP. The four-week window enabled the initially strong stimulus control of taking the PTP to fade. Then, the researchers compared these ten posts to the first ten posts for the same period the year before the study participant took the PTP. The aim was to correct for any calendar-based differences in one's Facebook sharing. For example, college students may share different types of posts during the school year than during break. Thus, if someone took the PTP on May 1, 2017, the post-pledge sharing evaluation period began on May 29, 2017 with the first 10 news-relevant posts, while the comparison period was the first 10 news-relevant posts staring on May 29, 2016.

Two coders coded the posts of each of the 21 study participants, 10 before the participant took the PTP and 10 after, for a total of 420 individual pieces of data. The coders evaluated both the post and the person's engagement in comments on that post as a total rating for each individual post with the goal of approximating the impact of each post on social media followers, as followers will pay attention both to the original post and the comments on the post.

The sharing was coded according to quality, from the lowest alignment with the PTP to the highest alignment. The coders - both of whom had graduate-level training, one in a PhD program and one in an MD program - were trained on a series of posts until they had a high level of agreement in their coding. The guidelines were as follows:

- 1 (Lowest): the content is misinformation, whether a news article or meme or personal post.

- 2: the content is accurate, but comes from an unreliable source, even if the post itself does not contain misinformation.

- 3: the content is accurate, but it is satire without indicating it is satire; or the headline does not match the article without the person making the post indicating that the headline does not match the article; or it is a personal post or meme that does not cite sources.

- 4: the content is fine, with no problems

- 5 (Highest): the content is specifically oriented to fighting misinformation and promote truth 


\section{Results}

It is important to evaluate inter-coder reliability between the two coders, and a typical approach to this is to calculate Krippendorff's alpha, a measurement of agreement among coders of data, designed to indicate their reliability. It ranges from 0 to 1 , whereas 0 indicates no agreement between the coders and 1 indicates perfect agreement. Strong coder reliability is indicated by alpha $\geq .800$, and in cases where it is acceptable to have more tentative conclusions, alpha $\geq .667$ is at the lowest acceptable limit (Krippendorf, 2004). The alpha for the two coders was .85, suggesting a good inter-coder reliability. We can assume that the coders agreed substantially on whether a Facebook post was in alignment with the PTP.

To evaluate the data, we took the average coding between the two coders, which left us with a single estimate per person per post (21 alignment scores before, and 21 alignment scores after taking the PTP). Data were tested for the statistical assumptions for a paired t-test: 1) normal distribution of the relevant variable and 2) homogeneity of variance. To evaluate the first assumption, a Shapiro-Wilk test was performed, indicating that the data do not significantly differ from a normal distribution, $\mathrm{W}=0.95, \mathrm{p}$-value $=0.08$.

Following that, a Levene-Test was conducted to assess the homogeneity of variance. The test indicates that there might be significant difference in variances between the groups, $F=4.069$, $p$ value $=0.0504$. Thus, heterogeneity of variance has to be assumed.

Given that all statistical assumptions except for the homogeneity of variances are met, a paired non-parametric t-test is estimated in order to examine whether Pro-Truth Pledge Alignment is significantly different after taking the PTP.

The null hypothesis $\mathrm{HO}$ for the paired t-test states that there is no significant alignment difference before and after taking the PTP and the alternative hypothesis $\mathrm{H} 1$ proposes a significant difference. There was a significant difference in the scores for Pledge Alignment before $(\mathrm{M}=2.49$, $\mathrm{SD}=0.60)$ and after $(\mathrm{M}=3.65, \mathrm{SD}=0.41)$ taking the PTP; $t(20)=-8.86, p<0.001$. An estimation of the effect size indicates that the found difference can be considered to be large (Cohen's d=1.93). Thus hypothesis $\mathrm{H} 0$ can be rejected in favor of hypothesis $\mathrm{H} 1$. These results suggest that taking the PTP had a statistically significant effect on behavior change in favor of more truthful sharing on Facebook.

Figure 1 provides a visual representation of the results. The thick black line shows the median. The thin lines represent change among individuals. All participants improved their sharing on Facebook to be more aligned with the PTP, some drastically.

\section{Discussion}

This study examined the effects of taking the PTP on people's behavior on their Facebook profiles, and confirmed that pledge-takers posted more truthful news stories four weeks after taking the PTP. The improvement was statistically significant, averaging about 1 unit on a 1-5 scale. This observed behavior change may support the assumption that pledge-takers also behaved more truthfully on other people's profiles and in groups, even though we have no realistic way of observing that. This study thus provides evidence that people behaved more honestly on Facebook because they signed the PTP, and therefore decreased the spread of misinformation on social media. By extension, these findings suggest that pledge-takers may practice more truthful behavior 


\section{Pro Truth-Pledge Alignment Before \& After PTP \\ 5- T-test, $p=0.000000023$}

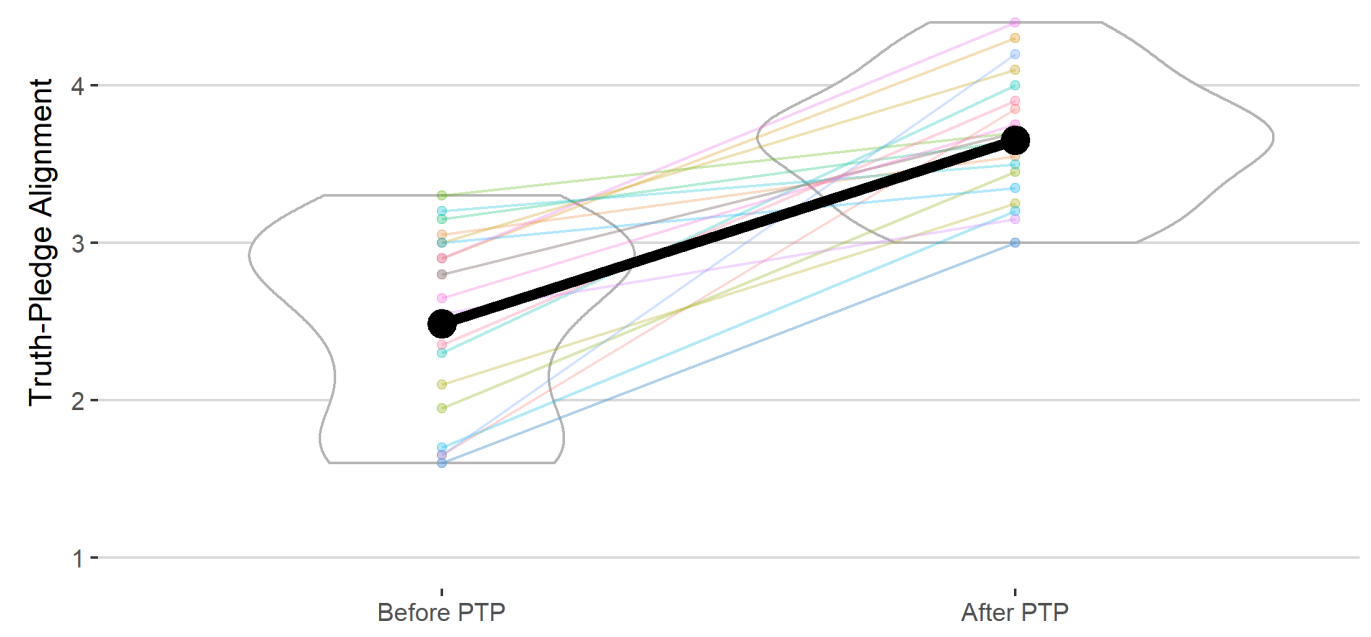

Figure 1. The results of PTP alignment before and after taking the PTP.

in other areas of their civic engagement. Further research is needed to determine whether that is indeed the case.

As a preliminary study of the efficacy of the PTP, there are some limitations that may inform future research. Organizations often present honor codes or pledges in a non-voluntary context, such as when students are presented with an honor code with an implicit expectation that they sign it in order to attend the college of their choice. As the PTP is a voluntary pledge, extension of these results to a non-voluntary pledge may not be assumed. For this type of analysis, further research is needed. In the future, we plan to replicate this study with a larger sample size, and also conduct studies with control groups to evaluate further the efficacy of the PTP changing behavior.

\section{General Discussion}

To solve the problem of private citizens sharing fake news and public figures engaging in deception to win and maintain power, prominent researchers in the field suggest that we need techno-cognitive solutions, those that combine technology with psychological principles. The PTP, which combines psychology research with online mechanisms of implementation and propagation, and crowd-sources fact-checking, is one such intervention. It asks participants to commit to 12 behaviors which are intended to counteract a number of cognitive biases that contribute to people believing in and sharing misinformation, an essential aspect of the psychology research informing the content of the PTP itself. In addition to committing to the behaviors of the PTP, pledge-takers are encouraged to share about taking the PTP on their social media, to put markers of taking the PTP on their online profiles, and to fact-check other pledge-takers, which is the crowd-sourcing component. The PTP uses methods shown by psychology research on environmental pollution as crucial to addressing tragedies of the commons (Milinsk, Semmann, \& Krambeck, 2002; Van Vugt, 2009). It provides information about the credibility of those who sign it, as well as information about what it means to orient toward the truth and what constitutes 
credible information sources. It appeals to the identity of people who value honesty and derive reinforcement from being recognized for their honesty.

This techno-cognitive solution has shown some early signs of effectiveness. To be effective requires that we see evidence of: 1) people taking the PTP, and 2) people abiding by the behaviors of the PTP. We have clear evidence of people taking the PTP, and now we have preliminary evidence of its effectiveness in bringing about behavior change. Evidence indicate that at least some pledge-takers change their behavior after the pledge, including public figures. Our empirical study shows that pledge-takers behave more truthfully on Facebook after taking the PTP. Future research should test the effectiveness of this impact, and the maintenance of the effects. In the meantime, these data suggest the PTP is valuable, and it is beneficial to encourage the widespread adoption of the Pro-Truth Pledge by all citizens and public figures who care about addressing the problem of fake news and post-truth politics.

\section{References}

Allcott, H., \& Gentzkow, M. (2017). Social media and fake news in the 2016 election. Journal of Economic Perspectives, 31(2), 211-236. doi:10.3386/w23089.

Ariely, D., \& Jones, S. (2012). The honest truth about dishonesty: How we lie to everyone--especially others (Vol. 336). New York: Harper Collins.

Ariely, D., \& Wertenbroch, K. (2002). Procrastination, deadlines, and performance: Self-control by precommitment. Psychological Science, 13(3), 219-224. doi:10.1111/1467-9280.00441.

Barrera, O., Guriev, S., Henry, E., \& Zhuravskaya, E. (2017). Facts, alternative facts, and fact checking in times of post-truth politics (No. 12220). CEPR Discussion Papers.

Baum, W. M. (1994). Understanding behaviorism: Science, behavior, and culture. New York: Harper Collins.

Blake, A. (2018, April 3). A new study suggests fake news might have won Donald Trump the 2016 election. Washington Post, Retrieved from: https://www.washingtonpost.com/news/the-fix/wp/2018/04/03/a-new-studysuggests-fake-news-might-have-won-donald-trump-the-2016-election/?utm term=.3be2b05dd93d

Booth, R., Weaver, M., Hern, A., \& Walker, S. (2017, November 14). Russia used hundreds of fake accounts to tweet about Brexit, data shows. The Guardian,

Retrieved from: https://www.theguardian.com/world/2017/nov/14/how-400-russia-run-fake-accounts-postedbogus-brexit-tweets

Brückner, H., \& Bearman, P. (2005). After the promise: The STD consequences of adolescent virginity pledges. Journal of Adolescent Health, 36(4), 271-278. doi:10.1016/j.jadohealth.2005.01.005.

Burn, S. M. (1991). Social psychology and the stimulation of recycling behaviors: The block leader approach. Journal of Applied Social Psychology, 21(8), 611-629. doi:10.1111/j.1559-1816.1991.tb00539.x.

Casadesus-Masanell, R., \& Ricart, J. (2011). How to design a winning competitive position. Harvard Business Review, 89(1/2), 100-107. doi:10.1016/b978-0-7506-8548-1.50010-9.

Cillizza, C. (2016, November 2). How the heck can voters think Donald Trump is more honest than Hillary Clinton? Washington Post, Retrieved from: https://www.washingtonpost.com/news/thefix/wp/2016/11/02/donald-trump-hasnt-told-the-truth-repeatedly-in-this-campaign-voters-still-think-he-ismore-honest-than-hillary-clinton/?utm_term=.0f490d1b4201.

Connelly, B. L., Certo, S. T., Ireland, R. D., \& Reutzel, C. R. (2011). Signaling theory: A review and assessment. Journal of Management, 37(1), 39-67. doi:10.1177/0149206310388419.

Correia, V., \& Festinger, L. (2014). Biased argumentation and critical thinking. Bern: Peter Lang.

Dietz, T., Ostrom, E., \& Stern, P. C. (2003). The struggle to govern the commons. Science, 302, 1907-1912. doi: $10.1126 /$ science. 1091015 .

Dunning, D. (2011). The Dunning-Kruger effect. Advances in Experimental Social Psychology, 44, $247-296$. doi:10.1016/b978-0-12-385522-0.00005-6.

Ehrlinger, J., Johnson, K., Banner, M., Dunning, D., \& Kruger, J. (2008). Why the unskilled are unaware: Further explorations of (absent) self-insight among the incompetent. Organizational Behavior and Human Decision Processes, 105(1), 98-121. doi:10.1016/j.obhdp.2007.05.002.

Fang-yuan, L. U. (2007). Evolutionary game analysis on environmental pollution problem. Systems EngineeringTheory \& Practice, 9, 148-152. 


\section{THE PRO-TRUTH PLEDGE}

Farand, C. (2017, April 22). French social media awash with fake news stories from sources 'exposed to Russian influence' ahead of presidential election. The Independent, Retrieved from:

http://www.independent.co.uk/news/world/europe/french-voters-deluge-fake-news-stories-facebook-twitterrussian-influence-days-before-election-a7696506.html

Fazio, L. K., Brashier, N. M., Payne, B. K., \& Marsh, E. J. (2015). Knowledge does not protect against illusory truth. Journal of Experimental Psychology: General, 144(5), 993. doi:10.1037/xge0000098.

Festinger, L. (1975). A theory of cognitive dissonance. Stanford, CA: Stanford University Press.

Festinger, L. (1962). Cognitive dissonance. Scientific American, 207(4), 93-106. doi: 10.1038/scientificamerican1062-93

Garrett, R. K., \& Weeks, B. E. (2013). The promise and peril of real-time corrections to political misperceptions. In Proceedings of the 2013 conference on Computer supported cooperative work, pp. 1047-1058. ACM. doi:10.1145/2441776.2441895.

Gino, F., Norton, M. I., \& Ariely, D. (2010). The counterfeit self. Psychological Science, 21(5), 712-720. doi: $10.1177 / 0956797610366545$

Gottfried, J., \& Shearer, E. (2016). News use across social media platforms 2016. Pew Research Center, May 26. Accessed August 28, 2017. http://www. journalism.org/2016/05/26/news-use-acrosssocial-media-platforms2016.

Green, J, \& Issenberg, S. (2016). Inside the Trump bunker, with days to go. Bloomberg Businessweek, October 27, 2016. https://www.bloomberg.com/news/articles/2016-10-27/inside-the-trump-bunker-with-12-days-to-go

Griskevicius, V., Tybur, J. M.. \& Van den Bergh, B. (2010). Going green to be seen: Status, reputation, and conspicuous conservation. Journal of Personality and Social Psychology, 98(3), 392-404. doi: $10.1037 / \mathrm{a} 0017346$.

Guadagno, R. E., \& Cialdini, R. B. (2010). Preference for consistency and social influence: A review of current research findings. Social Influence, 5(3), 152-163. doi:10.1080/15534510903332378.

Hanley, N., \& Folmer, H. (1998). Game theory and the environment. Edward Elgar.

Hardin, G. (1968). Tragedy of the commons. Science, 162(3859), 1243-1248. doi:10.1126/science.162.3859.1243

Hatfield, E., Cacioppo, J. T., \& Rapson, R. L. (1993). Emotional contagion. Current Directions in Psychological Science, 2(3), 96-100. doi:10.1111/1467-8721.ep10770953.

Hayes, S. C., Barnes-Holmes, D., \& Roche, B. (Eds.). (2001). Relational frame theory: A post-Skinnerian account of human language and cognition. Springer Science \& Business Media.

Hayes, S. C., Gifford, E. V., Hayes, G. J. (1998). Moral behavior and the development of verbal regulation. The Behavior Analyst, 21(2), 253-279. doi: 10.1007/BF03391967

Hirt, E. R., \& Markman, K. D. (1995). Multiple explanation: A consider-an-alternative strategy for debiasing judgments. Journal of Personality and Social Psychology, 69(6), 1069-1086. doi:10.1037//00223514.69.6.1069.

Hopper, J. R., \& Nielsen, J. M. (1991). Recycling as altruistic behavior. Environment and Behavior, 23(2), 195-220. doi: $10.1177 / 0013916591232004$.

Huppke, R. (2017, December 11). Trump calls media 'stain on America,' but he keeps lying. Chicago Tribune, Retrieved from: http://www.chicagotribune.com/news/opinion/huppke/ct-met-trump-fake-news-media-cnnhuppke-20171210-story.html

Imgur (2017). Imgur: The most awesome images on the internet. Last modified May 24, 2017. http://imgur.com/a/A8IOY.

Johnson, E. J., Shu, S. B., Dellaert, B. G., Fox, C., Goldstein, D. G., Häubl, G.,...Weber, E. U. (2012). Beyond nudges: Tools of a choice architecture. Marketing Letters, 23(2), 487-504. doi:10.1007/s11002-012-9186-1.

Jolls, C., Sunstein, C. R., \& Thaler, R. (1998). A behavioral approach to law and economics. Stanford Law Review, 50(5), 1471. doi:10.2307/1229304.

Katzev, R. D., \& Pardini, A. U. (1987). The comparative effectiveness of reward and commitment approaches in motivating community recycling. Journal of Environmental Systems, 17(2), 93-113. doi:10.2190/xv00-dd4bepeh-en5r.

Kerin, R. A., Varadarajan, P. R., \& Peterson, R. A. (1992). First-mover advantage: A synthesis, conceptual framework, and research propositions. Journal of Marketing, 56(4), 33. doi:10.2307/1251985.

Kray, L. J., \& Galinsky, A. D. (2003). The debiasing effect of counterfactual mind-sets: Increasing the search for disconfirmatory information in group decisions. Organizational Behavior and Human Decision Processes, 91(1), 69-81. doi:10.1016/s0749-5978(02)00534-4.

Krippendorff, K. (2004). Content analysis: An introduction to its methodology. Thousand Oaks, California: Sage. 


\section{TSIPURSKY, VOTTA, \& ROOSE}

Kruger, J., \& Dunning, D. (1999). Unskilled and unaware of it: How difficulties in recognizing one's own incompetence lead to inflated self-assessments. Journal of Personality and Social Psychology, 77(6), 11211134. doi:10.1037//0022-3514.77.6.1121.

Kwong, J. (2017, November 18). Why Clinton lost: What Russia did to control the American mind and put Trump in the White House. Newsweek, Retrieved from: http://www.newsweek.com/how-russian-trolls-targeted-2016election-merry-go-round-lies-715912

Lazer, D.M., Baum, M.A., Benkler, Y., Berinsky, A.J., Greenhill, K.M., Menczer, F.,... Schudson, M. (2018). The science of fake news. Science, 359(6380), 1094-1096. https://doi.org/10.1126/science.aao2998

Lewandowsky, S., Ecker, U. K., \& Cook, J. (2017). Beyond Misinformation: Understanding and Coping with the "Post-Truth" Era. Journal of Applied Research in Memory and Cognition, 6(4), 353-369. https://doi.org/10.1016/j.jarmac.2017.07.008

Lilienfeld, S. O., Ammirati, R., \& Landfield, K. (2009). Giving debiasing away: Can psychological research on correcting cognitive errors promote human welfare? Perspectives on Psychological Science, 4(4), 390-398. doi:10.1111/j.1745-6924.2009.01144.x.

Lindner, M. (2016, November 9). Block. Mute. Unfriend. Tensions rise on Facebook after election results. Chicago Tribune, Retrieved from: http://www.chicagotribune.com/lifestyles/ct-facebook-election-reaction-family-110920161109-story.html

Lord, K. R (1994). Motivating recycling behavior: A quasiexperimental investigation of message and source strategies. Psychology and Marketing, 11(4), 341-358. doi:10.1002/mar.4220110404.

Mann, H., Garcia-Rada, X., Houser, D., \& Ariely. D. (2014). Everybody else is doing it: Exploring social transmission of lying behavior. PloS One, 9(10), e109591. doi:10.1371/journal.pone.0109591.

Martino, S. C., Elliott, M. N., Collins, R. L., Kanouse, D. E.. \& Berry, S. H. (2008). Virginity pledges among the willing: Delays in first intercourse and consistency of condom use. Journal of Adolescent Health, 43(4), 341348. doi:10.1016/j.jadohealth.2008.02.018.

Mazar, N., Amir, O., \& Ariely, D. (2006). Dishonesty in everyday life and its policy implications. Journal of Public Policy \& Marketing, 25(1), 117-126. doi:10.1509/jppm.25.1.117.

Mazar, N., Amir, O., \& Ariely, D. (2008a). More ways to cheat-expanding the scope of dishonesty. Journal of Marketing Research, 45(6), 651-653.

Mazar, N., Amir, O., \& Ariely, D. (2008b). The dishonesty of honest people: A theory of self-concept maintenance. Journal of Marketing Research, 45(6), 633-644. doi:10.1509/jmkr.45.6.633.

McCabe, D. L., \& Trevino, L. K. (1993). Academic dishonesty: Honor codes and other contextual influences. The Journal of Higher Education, 64(5), 522. doi:10.2307/2959991.

McCabe, D. L., Trevino, L. K., \& Butterfield, K. D. (1999). Academic integrity in honor code and non-honor code environments: A qualitative investigation. The Journal of Higher Education, 70(2), 211. doi:10.2307/2649128.

Michael, J. (1982). Distinguishing between discriminative and motivational functions of stimuli. Journal of the experimental analysis of behavior, 37(1), 149-155. https://doi.org/10.1901/jeab.1982.37-149

Milinski, M., Semmann, D., \& Krambeck, H. J. (2002). Reputation helps solve the 'Tragedy of the Commons.' Nature, 415(6870), 424-426. doi:10.1038/415424a.

Mullen, B., Brown, R., \& Smith, C. (1992). Ingroup bias as a function of salience, relevance, and status: An integration. European Journal of Social Psychology, 22(2), 103-122. doi:10.1002/ejsp.2420220202.

Myers, T. A., Maibach, E. W., Roser-Renouf, C., Akerlof, K., \& Leiserowitz, A. A. (2013). The relationship between personal experience and belief in the reality of global warming. Nature Climate Change, 3(4), 343347. doi:10.1038/nclimate 1754 .

Nickerson, R. S (1998). Confirmation bias: A ubiquitous phenomenon in many guises. Review of General Psychology, 2(2), 175-220. doi:10.1037/1089-2680.2.2.175.

Nyhan, B., \& Reifler, J. (2015). The effect of fact-checking on elites: A field experiment on U.S. state legislators. American Journal of Political Science, 59(3), 628-640.doi:10.1111/ajps.12162.

Oskamp, S., Harrington, M. J., Edwards, T. C., Sherwood, D. L.. Okuda, S. M., \& Swanson, D. C. (1991). Factors influencing household recycling behavior. Environment and Behavior, 23(4), 494-519. doi: $10.1177 / 0013916591234005$.

Ostrom, E. (2015). Governing the commons. New York: Cambridge University Press. https://doi.org/10.1017/CBO9781316423936

Oxford Dictionary | English (2016). Word of the Year 2016 Is... Oxford Dictionaries. Accessed August 28, 2017. https://en.oxforddictionaries.com/word-of-the-year/word-of-the-year-2016. 


\section{THE PRO-TRUTH PLEDGE}

Palmer, E. (2017, November 18). Spain Catalonia: Did Russian 'fake news' stir things up? BBC News, Retrieved from: http://www.bbc.com/news/world-europe-41981539

Pennycook, G., Cheyne, J. A., Koehler, D. J., \& Fugelsang, J. A. (2013). Belief bias during reasoning among religious believers and skeptics. Psychonomic Bulletin \& Review, 20(4), 806-811. doi: 10.3758/s13423-0130394-3.

Pew Research Center. (2016, May 26). News use across social media platforms 2016 | Pew Research Center. Retrieved from: http://www.journalism.org/2016/05/26/news-use-across-social-media-platforms-2016/.

Pew Research Center. (2018, Feb 5). Social media fact sheet. Retrieved from: http://www.pewinternet.org/factsheet/social-media/

Pro-Truth Pledge (2017). Pro-Truth Pledge. Accessed August 28, 2017. Retrieved from: https://www.protruthpledge.org/.

Pro-Truth Pledge (2017). Pro-Truth Pledge FAQs. Accessed August 28, 2017. Retrieved from: https://www.protruthpledge.org/misinformation/.

Pro-Truth Pledge (2017). Pro-Truth Pledge Search Engine. Accessed August 28, 2017. Retrieved from: https://www.protruthpledge.org/facts-search-engine/.

Rasmussen Reports. (2016). Voters don't trust media fact-checking. Last modified September 30, 2016. Retrieved from:

http://www.rasmussenreports.com/public_content/politics/general_politics/september_2016/voters_don_t_trust media_fact_checking.

Roche, B., Barnes-Holmes, Y., Barnes-Holmes, D., Stewart, I., O’Hora, D. (2002). Relational frame theory: A new paradigm for the analysis of social behavior. The Behavior Analyst, 25(1), p. 75-91. doi: 10.1007/BF03392046

Selinger, E., \& Whyte, K. (2011). Is there a right way to nudge? The practice and ethics of choice architecture. Sociology Compass, 5(10), 923-935. doi:10.1111/j.1751-9020.2011.00413.x.

Sheldon, O. J., Dunning, D., \& Ames, D. R. (2014). Emotionally unskilled, unaware, and uninterested in learning more: Reactions to feedback about deficits in emotional intelligence. Journal of Applied Psychology, 99(1), 125-137. doi:10.1037/a0034138.

Shuster, S. (2017, August 2017). Russia has launched a fake news war on Europe. Now Germany is fighting back. Time, Retrieved from: http://time.com/4889471/germany-election-russia-fake-news-angela-merkel/

Silverman, C. (2016, August 28). This analysis shows how fake election news stories outperformed real news on Facebook. BuzzFeed News, Retrieved from: https://www.buzzfeed.com/craigsilverman/viral-fake-electionnews-outperformed-real-news-on-facebook?utm_term=.1syjR21epR\#.edLdEVoz5E

Silverman, C., \& Singer-Vine, J. (2016, August 28). Most Americans who see fake news believe it, new survey says. BuzzFeed News, Retrieved from: https://www.buzzfeed.com/craigsilverman/fake-newssurvey?utm_term=.bxym5zP245\#.argg0P1BD0

Skinner, B. F. (1953). Science and human behavior. Simon and Schuster.

Skinner, B. F. (1957). Verbal behavior. New York: Appleton. https://doi.org/10.1037/11256-000

Skinner, B. F. (1971). Beyond freedom and dignity. New York: Bantam Books.

Skinner, B. F. (1974) About behaviorism. New York: Alfred A.

Statista. (2017). Number of monthly active Twitter users worldwide from the $1^{\text {st }}$ quarter 2010 to $4^{\text {th }}$ quarter 2017 (in millions). Retrieved from: https://www.statista.com/statistics/282087/number-of-monthly-active-twitter-users/

Subramanian, S. (2017, February 15). Inside the Macedonian fake-news complex. Wired, Retrieved from: https://www.wired.com/2017/02/veles-macedonia-fake-news/

Sunstein, C. R., \& Thaler, R. H. (2003a). Libertarian paternalism. The American Economic Review, 93(2), 175-179. doi:10.1017/cbo9780511790850.009.

Sunstein, C. R., \& Thaler, R. H. (2003b). Libertarian paternalism is not an oxymoron. University of Chicago Public Law \& Legal Theory Working Paper, 43. doi:10.2139/ssrn.405940.

Swift, A. (2016). Americans' trust in mass media sinks to new low. Gallup, September 14, 2016. http://www.gallup.com/poll/195542/americans-trust-mass-media-sinks-new-low.aspx.

Swire, B., Berinsky, A. J., Lewandowsky, S., \& Ecker, U. K. (2017). Processing political misinformation: Comprehending the trump phenomenon. Royal Society Open Science, 4(3), 160802. doi: 10.1098/rsos.160802.

Thaler, R. H., \& Sunstein, C. R. (2008) Nudge: Improving decisions about health, wealth, and happiness. New York: Penguin Books.

Thaler, R. H., Sunstein, C. R., \& Balz, J. P. (2014). Choice architecture. SSRN Electronic Journal. doi: $10.2139 /$ ssrn. 1583509 . 


\section{TSIPURSKY, VOTTA, \& ROOSE}

Torneke, N. (2010). Learning RFT: An introduction to relational frame theory and its clinical application. New Harbinger Publications.

Tyler, T. R., \& Degoey, P. (1995). Collective restraint in social dilemmas: Procedural justice and social identification effects on support for authorities. Journal of Personality and Social Psychology, 69(3), 482-497. doi:10.1037//0022-3514.69.3.482.

Van Vugt, M. (2001). Community identification moderating the impact of financial incentives in a natural social dilemma: Water conservation. Personality and Social Psychology Bulletin, 27(11), 1440-1449. doi: $10.1177 / 01461672012711005$.

Van Vugt, M. (2009). Averting the tragedy of the commons. Current Directions in Psychological Science, 18(3), 169-173. doi:10.1111/j.1467-8721.2009.01630.x.

Verkuyten, M., \& Nekuee, S. (1999). Ingroup bias: The effect of self-stereotyping, identification and group threat. European Journal of Social Psychology, 29(23), 411-418. doi:10.1002/(SICI)10990992(199903/05)29:2/3<411::AID-EJSP952>3.0.CO;2-8.

Vining, J., \& Ebreo, A. (1992). Predicting recycling behavior from global and specific environmental attitudes and changes in recycling opportunities. Journal of Applied Social Psychology, 22(20), 1580-1607. doi:10.1111/j.1559-1816.1992.tb01758.x.

Vogler, J. (2000). The global commons: environmental and technological governance (Vol. 9). John Wiley \& Sons.

Vraga, E. K., Tully, M., \& Rojas, H. (2009). Media literacy training reduces perception of bias. Newspaper Research Journal, 30(4), 68-81. doi:10.1177/1077695815623399.

Westman, M., Eden, D., \& Shirom, A. (1985). Job stress, cigarette smoking and cessation: The conditioning effects of peer support. Social Science \& Medicine, 20(6), 637-644. doi:10.1016/0277-9536(85)90402-2.

Wray, A. M., Freund, R. A., \& Dougher, M. J. (2009). A behavior-analytic account of cognitive bias in clinical populations. The Behavior Analyst, 32(1), 29-49. doi:10.1007/BF03392174

Zimmerman, R. S., \& Connor, C. (1989). Health promotion in context: The effects of significant others on health behavior change. Health Education Quarterly, 16(1), 57-75. doi:10.1177/109019818901600108. 